\title{
Suplementação de aminoácidos na fermentação alcoólica de mostos de melaço e xarope de cana-de-açúcar empregando linhagem industrial CAT-1
}

\author{
Camila de Souza Varize ${ }^{a^{*}}$, Renata Maria Christofoleti-Furlan ${ }^{a}$, Mariane Soares Raposo ${ }^{a}$, \\ Carolina Tieppo Camarozano ${ }^{\mathrm{a}}$, Lucas Dantas Lopes ${ }^{\mathrm{a}}$, Elisangela de Souza Miranda Muynarsk ${ }^{\mathrm{a}}$, \\ Thalita Peixoto Basso ${ }^{\mathrm{a}}$, Luiz Carlos Basso ${ }^{\mathrm{a}}$
}

\footnotetext{
${ }^{a}$ Escola Superior de Agricultura Luiz de Queiroz (USP), Brasil

*Autor correspondente (camilasv@usp.br)
}

\section{N F O}

\section{Keywords}

histidine

amino acid

supplementation

alcoholic fermentation

S. cerevisiae

\section{Palavras-chaves histidina suplementação de aminoácidos fermentação alcoólica S. cerevisiae}

\begin{abstract}
A B S T R A C T
Amino acid supplementation in alcoholic fermentation of molasses must and sugarcane syrup using CAT1 industrial lineage.

Nitrogen supplementation may contribute to higher tolerance of $S$. cerevisiae strains to the different deleterious conditions, such as those that are faced in the Brazilian ethanol production. The present study evaluated the influence of amino acid supplementation under the growth and cell viability of CAT-1 industrial strain under conditions of ethanolic and osmotic stress (YNB medium with 10 and 12\% v/v ethanol and molasses must with 15, 20, 25 and 30\% ART). Amino acid supplementation was also evaluated in fermentations of sugarcane molasses and syrup, using cell recycle. The results revealed that amino acid supplementation caused distinct effects on the physiological behavior of the yeast according to the medium/musts provided. Histidine supplementation favored the CAT-1 for higher growth and cell viability in molasses and syrup musts. The results showed that the supplementation of $200 \mathrm{mg} . \mathrm{L}^{-1} \mathrm{of}$ amino acid can favor or degrade the growth and viability of the CAT-1 in fermentations simulating Brazilian industrial conditions. Supplementation with histidine proved to be the most promising for increasing the tolerance of the industrial strain.
\end{abstract}

\section{R E S U M O}

A suplementação de fontes nitrogenadas pode contribuir para maior tolerância de linhagens de $S$. cerevisiae frente às diversas condições deletérias, como as que são enfrentadas no processo brasileiro de produção de etanol. O presente estudo avaliou a influência da suplementação de aminoácidos sob o crescimento e a viabilidade celular da linhagem industrial CAT-1 em condições de estresse etanólico e osmótico (meio YNB com 10 e 12\% v/v de etanol e mosto de melaço com 15, 20, 25 e 30\% de ART). A suplementação de aminoácidos também foi avaliada em fermentações de melaço e xarope de cana-deaçúcar, empregando reciclo (reaproveitamento) de células. Os resultados revelaram que a suplementação com aminoácidos ocasionou efeitos distintos no comportamento fisiológico da levedura de acordo com o meio/mosto fornecido. A suplementação com histidina favoreceu a linhagem CAT-1 para maior crescimento e viabilidade em mostos provenientes tanto de melaço quanto de xarope. Os resultados revelaram que a suplementação de $200 \mathrm{mg} . \mathrm{L}^{-1}$ de nitrogênio amínico proveniente de aminoácidos, adicionada aos diferentes mostos, pode favorecer ou depreciar o crescimento e viabilidade da linhagem CAT-1 em fermentações simulando as condições industriais brasileiras. A suplementação com histidina se mostrou a mais promissora para o aumento da tolerância da linhagem industrial CAT-1. 


\section{INTRODUÇÃO}

Compreender os fatores que interferem o processo de produção de etanol é de fundamental importância para contemplar uma fermentação com alta taxa de sobrevivência celular, desempenho fermentativo e consequentemente rendimento satisfatório (Basso et al., 2011; Lopes et al., 2016). Uma condição nutricional adequada pode favorecer as células de levedura, tornando-as aptas a sobreviver aos efeitos deletérios, encontrados durante a fermentação (Tropea et al., 2016). Além de açúcares fermentescíveis e compostos inorgânicos, o nitrogênio é um componente essencial para as células (Albers et al., 1996). Nesta conjuntura, a fonte de nitrogênio disponível no substrato durante o processo fermentativo tem influência direta sob o metabolismo e a fisiologia da levedura (Kalmokoff e Ingledew et al., 1985; Thomas e Ingledew, 1990; Basso et al., 2011). A tolerância, o crescimento/multiplicação celular, e, por conseguinte, o rendimento fermentativo do processo são exemplos de fatores influenciados pela disponibilidade de nitrogênio no meio (Thomas e Ingledew, 1990). Também é proposto que em $S$. cerevisiae a limitação de nitrogênio nas fermentações pode ocasionar a inativação de proteínas trasportadoras de sacarose (Badotti et al., 2008), sendo este o açúcar mais abundante no substrato empregado no processo brasileiro (Peters, 2006).

As várias fontes de nitrogênio usadas por leveduras são qualitativamente referidas como sendo preferidas ou não preferidas. Esta classificação foi empiricamente baseada em dois critérios: o primeiro é o quão bem os compostos individuais suportam o crescimento quando presentes como única fonte de nitrogênio, e o segundo critério reflete a descoberta de que as fontes preferenciais de nitrogênio geralmente provocam a repressão dos processos necessários para a utilização de fontes de nitrogênio não preferidas (Magasanik e Kaiser, 2002).

Leveduras $S$. cerevisiae preferencialmente utilizam o nitrogênio na forma amoniacal (NH4+) e, a partir do íon amônio, sintetizam todos os aminoácidos e bases nitrogenadas, necessários ao seu crescimento. Em condições de carência do íon amônio, o $\mathrm{N}$ amídico (na forma de ureia, por exemplo) ou amínico (na forma de aminoácidos) podem ser metabolizados por outras vias de utilização em S. $c e$ revisiae (Basso e Amorim, 2001). O nitrogênio contido no caldo de cana puro está majoritariamente disponível na forma assimilável, no entanto, é insuficiente para suprir a nutrição celular da levedura (Chen, 1993; Jeronimo et al., 2008). A suplementação com o sulfato de amônio ou com a ureia tem sido requerida pela indústria alcooleira por re- presentarem fontes de $\mathrm{N}$ mais econômicas. Contudo, apesar da suplementação com a ureia pouco afetar o pH do meio, a utilização do sulfato de amônio aumenta a acidez do meio externo, diminuindo a viabilidade e a multiplicação das células (Amorim et al., 1996). Estudar possíveis fontes de $\mathrm{N}$ e suas respectivas concentrações adequadas ao processo é de extrema relevância para aumentar as opções de suplementação atualmente disponíveis para a indústria. Ademais, alguns resíduos agroindustriais contêm altas concentrações de nitrogênio, torná-los um subproduto seria uma proposta promissora para o desenvolvimento sustentável (Woiciechowski et al., 2013). Para isso, seria preciso estudos extensivos sobre a ação das diferentes fontes de $\mathrm{N}$ assimiláveis pela levedura em substratos atualmente empregados nos processos de produção do bioetanol.

A capacidade de usar aminoácidos e outros compostos nitrogenados requer sua internalização e, consequentemente, as células de leveduras possuem múltiplas permeases para facilitar seu transporte através da membrana citoplasmática (Ljungdahl, 2009). A presença de aminoácidos no meio induz a expressão de várias permeases de especificidade ampla; portanto, os aminoácidos induzem a sua própria absorção. Esta resposta da transcrição é mediada pelo sensor Ssy1-Ptr3-Ssy5 (SPS) localizado na membrana citoplasmática (Ljungdahl, 2009).

Os aminoácidos podem ser referidos como unidades de construção, uma vez que desempenham funções vitais para a célula, como a síntese de enzimas e de componentes estruturais (Takagi et al., 1997; Morita et al., 2002). Segundo Hu et al. (2005) os aminoácidos isoleucina, metionina e fenilalanina podem aumentar a tolerância de $S$. cerevisiae em condição de estresse etanólico. De acordo com os autores, a maior tolerância das células foi decorrente da incorporação dos aminoácidos suplementares na membrana citoplasmática, o que possivelmente levou à maior capacidade de neutralizar o efeito de fluidização exercido pelo etanol.

Outro estudo identificou que uma linhagem sobre expressando a prolina também apresentou maior viabilidade em condições de estresse alcoólico e, além disso, maior resistência ao congelamento, dessecação e estresse oxidativo foi observada (Takagi, 2008). A suplementação com o ácido glutâmico também tem sido apontada por gerar benefícios às células de $S$. cerevisiae, uma vez que promoveu um crescimento maior e mais acelerado em substrato derivado de trigo (Thomas e Ingledew, 1990). Sendo assim, é possível hipotetizar que alguns aminoácidos podem atuar não somente como fonte de $\mathrm{N}$, mas também como um constituinte protetor de membrana, aumentando a viabilidade celular da levedura em situações adversas, 
como as que são encontradas no processo industrial da produção de etanol (Hu et al., 2005). Embora existam estudos relatando a influência dos aminoácidos na fisiologia de $S$. ceresisiae, submetida a diferentes condições de estresse, estudos destacando a ação dos mesmos atuando individualmente em fermentações de mostos derivados de cana-de-açúcar ainda são escassos.

Neste contexto, o presente estudo teve por objetivo avaliar a suplementação de nitrogênio amínico proveniente de aminoácidos no crescimento e viabilidade celular da levedura industrial CAT-1 em mostos de melaço e xarope de cana-de-açúcar.

\section{MATERIAL E MÉTODOS}

\section{Material biológico}

A linhagem industrial CAT-1 foi empregada no decorrer de todo o presente estudo, no qual realizaram-se testes de crescimento em microescala e experimentos fermentativos com reciclo de células, no intuito de avaliar a suplementação de $200 \mathrm{mg} . \mathrm{L}^{-}$ ${ }^{1}$ de $\mathrm{N}$ amínico proveniente de aminoácidos. Tal linhagem de levedura foi obtida/selecionada por Basso et al. (2008). O experimento foi inteiramente conduzido no Laboratório de Bioquímica e Tecnologia de Leveduras da Escola Superior de Agricultura Luiz de Queiroz, Universidade de São Paulo (ESALQ/USP).

\section{Testes de crescimento em microescala}

Testes de crescimento em microescala foram realizados em triplicata em um espectrofotômetro
TECAN (Densidade óptica/D.O. $600 \mathrm{~nm}$ ), por incubação de microplacas de 96 poços em condições microaeróbicas com leituras em intervalos de 2 horas a $30^{\circ} \mathrm{C}$, durante o período de 48 horas. Agitações prévias de 5 minutos antes de cada leitura foram realizadas. Para a montagem da microplaca, foi adicionado em cada poço:

- $20 \mu \mathrm{L}$ de solução de cada aminoácido (com 1.200 mg.L $\mathrm{L}^{-1}$ de $\mathrm{N}$ amínico), diluído com água e esterilizado em autoclave a $121^{\circ} \mathrm{C}$ por 20 minutos (Tabela 1 );

- $10 \mu \mathrm{L}$ de inóculo pré-crescido durante 48 horas em meio YEPD (2\% D-glicose, $1 \%$ de extrato de levedura e $1 \%$ de peptona bacteriológica);

- $90 \mu \mathrm{L}$ de mosto de melaço de cana com diferentes concentrações de ART (\%,p/v) e pH 5,0, ou $90 \mu \mathrm{L}$ de meio YNB $(0,93 \%$ YNB sem sulfato de amônio e aminoácidos, $2,70 \%$ D-glicose, $0,1 \%$ sulfato de amônio e $0,05 \%$ uréia) com diferentes níveis de etanol $(\%, \mathrm{v} / \mathrm{v})$ e $\mathrm{pH} 5,0$.

A concentração de cada aminoácido foi calculada para contribuir com $200 \mathrm{mg} . \mathrm{L}^{-1}$ de $\mathrm{N}$ amínico em $120 \mu \mathrm{L}$, sendo este o volume final de cada poço de microplaca (Tabela 1). As concentrações de uréia e sulfato de amônio foram calculadas para contribuir juntas com um total de $200 \mathrm{mg} . \mathrm{L}^{-1}$ de N amínico em um volume final de $120 \mu \mathrm{L}$. Os aminoácidos nas moléculas proteicas são sempre L-estereoisômeros, portanto, somente foram utilizados Laminoácidos.

Tabela 1 - Dados de peso molecular e concentração dos aminoácidos testados.

\begin{tabular}{|c|c|c|c|c|c|c|c|}
\hline & Aminoácidos & & $\begin{array}{c}\text { Peso mo- } \\
\text { lecular }\end{array}$ & $\begin{array}{c}\text { mg de N amí- } \\
\text { nico. } \mathrm{L}^{-1}(\text { por mili- } \\
\left.\text { mol. } \mathrm{L}^{-1}\right) \\
\end{array}$ & $\begin{array}{c}\text { mmolL }^{-1} \text { para } 1.200 \\
\text { mg de } N \text { amínico. } L^{-1} \\
(1200 * 14)\end{array}$ & 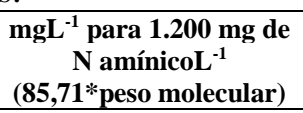 & $\begin{array}{c}\text { g. } \mathrm{L}^{-1} \text { para } \\
1.200 \mathrm{mg} \mathrm{de} \mathrm{N} \\
\text { amínico.. }{ }^{-1} \\
\end{array}$ \\
\hline 1 & Alanina & Ala & 89,1 & 14 & 85,71 & 7637,14 & 7,64 \\
\hline 2 & Arginina & Arg & 210,7 & 14 & 85,71 & 18060,00 & 18,06 \\
\hline 3 & Asparagina & Asn & 132,1 & 14 & 85,71 & 11322,86 & 11,32 \\
\hline 4 & Aspartato ou ácido aspártico & Asp & 133,1 & 14 & 85,71 & 11408,57 & 11,41 \\
\hline 5 & Cisteína & Cys & 175,6 & 14 & 85,71 & 15051,43 & 15,05 \\
\hline 6 & Fenilalanina & Phe & 165 & 14 & 85,71 & 14142,86 & 14,14 \\
\hline 7 & Glicina ou Glicocola & Gly & 75,1 & 14 & 85,71 & 6437,14 & 6,44 \\
\hline 8 & Glutamato ou ácido glutâmico & Glu & 147,1 & 14 & 85,71 & 12608,57 & 12,61 \\
\hline 9 & Glutamina & Gln & 146 & 14 & 85,71 & 12514,29 & 12,51 \\
\hline 10 & Histidina & His & 155 & 14 & 85,71 & 13285,71 & 13,29 \\
\hline 11 & Isoleucina & Ile & 131,2 & 14 & 85,71 & 11245,71 & 11,25 \\
\hline 12 & Leucina & Leu & 131,2 & 14 & 85,71 & 11245,71 & 11,25 \\
\hline 13 & Lisina & Lys & 182,7 & 14 & 85,71 & 15660,00 & 15,66 \\
\hline 14 & Metionina & Met & 149,21 & 14 & 85,71 & 12789,43 & 12,79 \\
\hline 15 & Prolina & Pro & 115,13 & 14 & 85,71 & 9868,29 & 9,87 \\
\hline 16 & Serina & Ser & 105,1 & 14 & 85,71 & 9008,57 & 9,01 \\
\hline 17 & Tirosina & Tyr & 181,2 & 14 & 85,71 & 15531,43 & 15,53 \\
\hline 18 & Treonina & Thr & 119,1 & 14 & 85,71 & 10208,57 & 10,21 \\
\hline 19 & Triptofano & Trp & 204,2 & 14 & 85,71 & 17502,86 & 17,50 \\
\hline 20 & Valina & Val & 117,2 & 14 & 85,71 & 10045,71 & 10,05 \\
\hline
\end{tabular}




\section{Determinação de $\mathrm{N}$ assimilável em melaço de cana-de-açúcar}

A dosagem de $\mathrm{N}$ assimilável ( $\mathrm{N}$ amínico $+\mathrm{N}$ amoniacal) pela levedura foi determinada em mosto de melaço de cana com $10 \%$ de ART. Inicialmente, o $\mathrm{pH}$ do mosto foi ajustado para $8,0 \mathrm{com} \mathrm{NaOH}(1,0$ mol. $\left.\mathrm{L}^{-1}\right)$, e adicionou-se $10 \mathrm{~mL}$ de $\mathrm{BaCl}_{2}(1,0$ mol. $\left.L^{-1}\right)$. Após 15 minutos, todo o volume foi adicionado em balão volumétrico de $200 \mathrm{~mL}$, onde se completou o volume com água desmineralizada. Todo o conteúdo do balão foi filtrado com papel filtro, desprezando os primeiros $10 \mathrm{~mL}$. Do filtrado transferiu-se $100 \mathrm{~mL}$ para um béquer, o $\mathrm{pH}$ foi novamente ajustado para 8,0 (NaOH, 1,0 mol. $\left.\mathrm{L}^{-1}\right) \mathrm{e}$ adicionou-se $25 \mathrm{~mL}$ de formaldeído com $\mathrm{pH}$ também ajustado para 8,0. Por meio de titulação de $\mathrm{NaOH}\left(1,0\right.$ mol.L $\left.\mathrm{L}^{-1}\right)$, e anotação do volume gasto, calculou-se a concentração de $\mathrm{N}$ assimilável (Filipe-Ribeiro e Mendes-Faia, 2007).

\section{Preparação de mostos a partir de melaço e xarope de cana-de-açúcar com suplementação de aminoácidos}

Os mostos oriundos do melaço ou xarope de cana-de-açúcar, utilizados nos experimentos fermentativos com reciclo de células, foram preparados a partir de diluição do melaço/xarope com água, para obter a porcentagem $(\%, \mathrm{p} / \mathrm{v})$ de ART desejada. Os mostos diluídos foram centrifugados a $10.000 \mathrm{rpm}$, sob $20^{\circ} \mathrm{C}$, durante 20 minutos e distribuídos em frascos erlenmeyer, os quais foram esterilizados a $121^{\circ} \mathrm{C}$ por 25 minutos. Paralelamente, preparou-se em frascos erlenmeyer de $50 \mathrm{~mL}$, uma solução de cada aminoácido contendo $2000 \mathrm{mg} . \mathrm{L}^{-1}$ de $\mathrm{N}$ amínico em $15 \mathrm{~mL}$ de água destilada, esterilizados a $121^{\circ} \mathrm{C}$ por 25 minutos.

Em câmara de fluxo, toda a solução estéril de cada L-aminoácido foi adicionada separadamente em garrafas pet com capacidade de $350 \mathrm{~mL}$ (previamente esterilizadas com água sanitária $10 \%$ e enxaguadas com água destilada), adicionando-se em seguida $135 \mathrm{~mL}$ de mosto de melaço ou xarope. A concentração dos aminoácidos foi calculada para $200 \mathrm{mg} . \mathrm{L}^{-1}$ de $\mathrm{N}$ amínico, obtendo-se $150 \mathrm{~mL}$ de volume final de mosto em cada garrafa pet. Os mostos foram estocados em congelador e degelados diariamente para a utilização em cada ciclo.

\section{Propagação de biomassa de levedura para experimentos fermentativos}

Para a propagação de biomassa, $150 \mu \mathrm{L}$ da cultura previamente armazenada em ultra-freezer (em solução com $20 \%$ de glicerol) foram transferidos para 2 tubos contendo $5 \mathrm{~mL}$ de meio YEPD (2\% D- glicose, $1 \%$ de extrato de levedura e $1 \%$ de peptona bacteriológica) sob incubação a $28^{\circ} \mathrm{C}$, durante 48 horas. Após o crescimento, todo o conteúdo dos tubos foi transferido para 2 frascos erlenmeyer contendo $150 \mathrm{~mL}$ de mosto de melaço de cana da Usina São Manoel com $10 \%$ de ART, pH 4,5, incubação a $30^{\circ} \mathrm{C}$, durante 48 horas. Posteriormente, o conteúdo total de cada erlenmeyer foi transferido para 2 frascos erlenmeyer contendo 1,2 L do mesmo mosto acima mencionado. Os frascos foram incubados a $30^{\circ} \mathrm{C}$, durante o período de 72 horas. Em seguida, a biomassa úmida foi resgatada por centrifugação (4000 rpm) para a condução do primeiro ciclo de fermentação. Todo o procedimento de propagação e resgate de biomassa úmida foi repetido para os experimentos fermentativos com reciclo de células.

\section{Experimentos fermentativos com suplementação de aminoácidos e reciclo de células}

Foram conduzidos dois experimentos fermentativos com reciclo de células, nos quais se empregou tubos de fundo cônico (Falcon) com capacidade de $15 \mathrm{~mL}$. No primeiro experimento, com duas repetições para cada tratamento com aminoácido (200 mg. $L^{-1}$ de $\mathrm{N}$ amínico), empregou-se mosto de melaço da Usina Açucareira São Manoel. No segundo, com três repetições para cada tratamento (200 mg. $L^{-1}$ de $\mathrm{N}$ amínico de aminoácido), empregou-se xarope de cana-de-açúcar da Usina São Martinho.

Em ambos os experimentos, para o inóculo do primeiro ciclo fermentativo, coletou-se por centrifugação (4.000 rpm) a biomassa da linhagem CAT1 da etapa de propagação, de modo que todos os tratamentos iniciassem o primeiro ciclo com o mesmo teor $(\mathrm{g})$ de fermento $(0,85 \mathrm{~g}$ no primeiro experimento e $0,76 \mathrm{~g}$ no segundo). Posteriormente, adicionou-se $8 \mathrm{~mL}$ de mosto de melaço, no caso do primeiro experimento e xarope de cana, no caso do segundo. As fermentações foram conduzidas a $30^{\circ} \mathrm{C}$. Os tubos foram mantidos em incubação a $30^{\circ} \mathrm{C}$ pelo período de 8 horas, e posteriormente foram mantidos na bancada em temperatura ambiente, até a realização do ciclo subsequente, no dia posterior. Ao final de cada ciclo fermentativo, a biomassa de levedura foi separada do substrato fermentado por centrifugação (4.000 rpm) e pesada. Então, adicionou-se $8 \mathrm{~mL}$ de mosto, conforme as condições acima descritas. Todo o procedimento foi repetido sucessivamente em 7 reciclos no primeiro experimento fermentativo, e em 3 reciclos no segundo. A concentração de ART $(\%, \mathrm{p} / \mathrm{v})$ do mosto foi aumentada gradualmente ao longo do primeiro experimento, onde os mostos tinham concen- 
trações de 12,15 e $20 \%$ de ART. No segundo experimento, no qual se utilizou xarope de cana, a concentração de ART foi de $20 \%$. Ao final de todos os ciclos mediu-se: o teor de etanol $(\%, \mathrm{v} / \mathrm{v})$ do vinho delevedurado, o peso da biomassa $(\mathrm{g})$ e a viabilidade celular (\%).

\section{Determinação de biomassa}

Os tubos de fundo cônico vazios foram pesados antes de iniciar os experimentos de fermentação com reciclo de células. Ao final de cada ciclo, após a separação dos vinhos, a biomassa úmida precipitada foi pesada (g), e por diferença de peso do tubo com e sem fermento, foi determinado o teor de biomassa úmida ao final de cada ciclo fermentativo.

\section{Determinação de etanol}

Foram transferidos $5 \mathrm{~mL}$ do vinho delevedurado para o interior de um microdestilador Kjeldahl (Piracicaba, Brasil). A partir da destilação por arraste de vapor, foi recolhido o material condensado em um balão volumétrico de $50 \mathrm{~mL}$, até completar o volume. As amostras destiladas foram transferidas para um densímetro digital Anton-Paar DMA-48 (Graz, Áustria) para a estimativa do teor de etanol $(\%, \mathrm{v} / \mathrm{v})$. O valor gerado pelo densímetro foi multiplicado por 10 de modo a compensar a diluição ocorrida na etapa de destilação.

\section{Determinação de viabilidade celular}

A viabilidade celular foi estimada em porcentagem por microscopia óptica, em objetiva de 40x, por coloração diferencial de células, utilizando-se uma solução de eritrosina em tampão de fosfato. As células viáveis (não coradas) e as células não viáveis (coradas de rosa) foram contadas com auxílio de uma câmara de Neubauer. A viabilidade foi expressa em função da proporção de células viáveis sobre o total de células contadas (viáveis e não viáveis) (Oliveira et al., 1996).

\section{Análises estatísticas}

Foram realizadas análises de variância (ANOVA) e testes de comparação de médias de Tukey no software R. As médias referentes às repetições de cada tratamento foram consideradas diferentes ao nível de 5\% de significância $(\mathrm{p}<0,05)$.

\section{RESULTADOS E DISCUSSÃO}

\section{Testes de crescimento em meio YNB com etanol}

O principal objetivo dos testes, nos quais se empregou meio YNB contendo 10 e $12 \%$ de etanol (v/v), foi avaliar a influência da suplementação dos aminoácidos no crescimento da linhagem CAT-1 quando exposta aos níveis de etanol encontrados na indústria. De acordo com Basso et al. (2008) na indústria do etanol, o caldo ou o melaço de cana de açúcar, utilizados como substratos no processo, resultam em produções nas concentrações de etanol de $8-11 \%(\mathrm{v} / \mathrm{v})$ dentro de um período de 6-11 horas a $32-35^{\circ} \mathrm{C}$.

Os testes de crescimento (D.O. $600 \mathrm{~nm}$ ) em meio YNB suplementado com $200 \mathrm{mg} . \mathrm{L}^{-1}$ de $\mathrm{N}$ amínico proveniente de aminoácido revelou que, quando o tratamento foi de $10 \%$ de etanol (v/v), no período de 48 horas somente o ácido aspártico $(0,760)$ conferiu maior crescimento em relação ao controle $(0,713)$ sem a suplementação de aminoácido (controle 1) (Figura 1). No entanto, a análise estatística revelou que estes valores de D.O. final (Asp e controle 1) não representam diferenças significativas. Sendo assim, no teste com $10 \%$ de etanol, nenhum aminoácido conferiu maior crescimento em relação ao controle 1, sem a suplementação.

Na figura 1, o Controle 1 refere-se a D.O. em meio YNB com $10 \%$ de etanol (v/v) sem a adição de aminoácido no mesmo período. O Controle 2 refere-se a D.O. em meio YNB sem a adição de etanol e aminoácido no mesmo período. Letras iguais não diferem ao nível de $5 \%$ de significância $(\mathrm{p}<0,05)$, de acordo com o teste de Tukey. Análises estatísticas só foram calculadas para os tratamentos com etanol. Neste mesmo meio, YNB, sem a adição de aminoácido e de etanol (controle 2), a linhagem CAT-1 apresentou uma D.O. de 0,881 no período de 48 horas (Figura 1). No que se refere à depreciação do crescimento, 11 aminoácidos conferiram menor crescimento em relação ao controle 1 , sendo estes: Leu, Pro, His, Ile, Val, Tyr, Met, Lys, Thr, Gln e Cys. A suplementação com Cys causou um crescimento significativamente menor em relação a todos os outros aminoácidos e controles 1 e 2 , sugerindo que possivelmente este aminoácido pode ter sido tóxico para a levedura nestas condições, uma vez que quase não houve crescimento após 48 horas (D.O. 0,012) (Figura 1).

Por outro lado, quando o teor de etanol foi de $12 \%(\mathrm{v} / \mathrm{v})$ no meio $\mathrm{YNB}$, a suplementação de glicina $(0,636)$ e de fenilalanina $(0,588)$ incrementaram significativamente o crescimento em relação ao controle $1(0,430)$ após 48 horas (Figura 2). A glicina é um aminoácido aquiral pequeno que desempenha um papel importante no metabolismo de carbono das células de levedura (Piper et al., 2000). Portanto, desempenha um papel importante no suporte a divisão celular (Wu 2009). As três rotas primárias de glicina são o metabolismo e a formação de serina via serina hidroximetiltransferase, a descarboxilação oxidativa através do sistema de clivagem da glicina (glicina sintase), e a formação de bases de nucleotídeos (Sinclair e Dawes, 1995). 


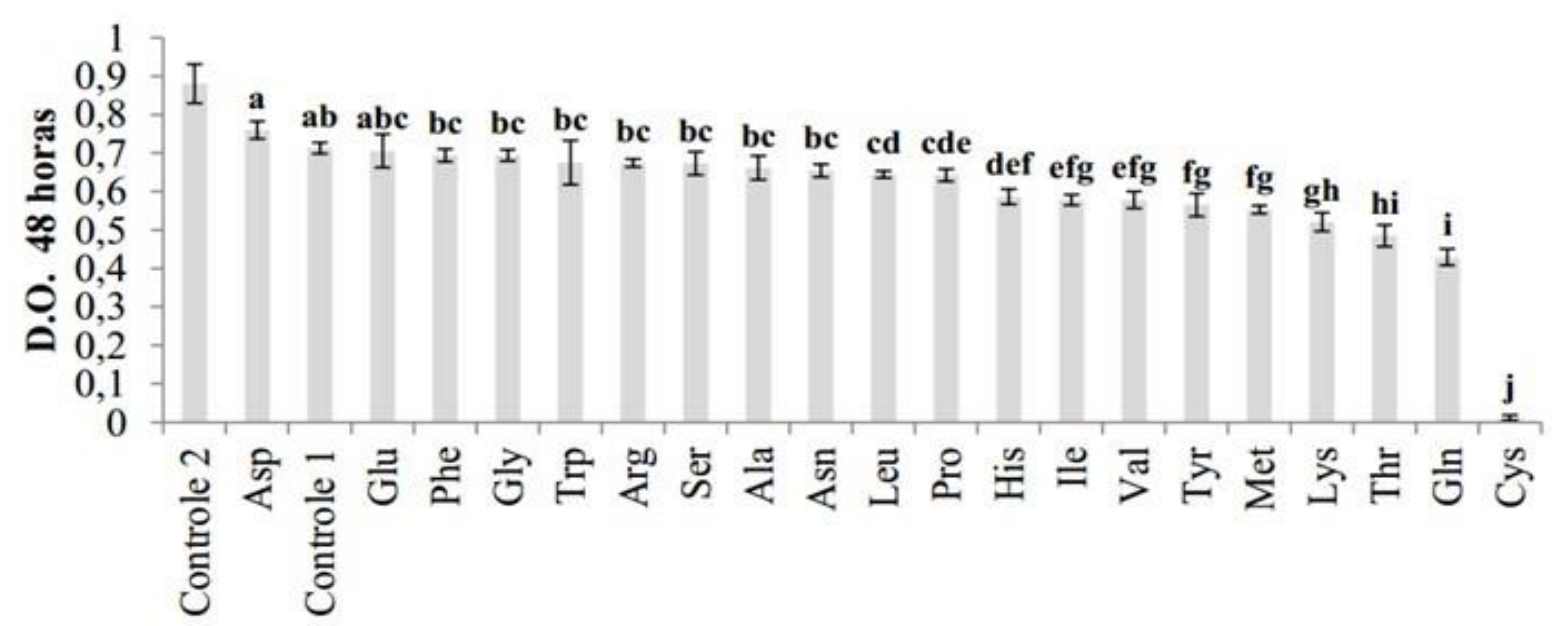

Aminoácidos

Figura 1 - Dados de D.O. (600nm) final e análises estatísticas da linhagem CAT-1 às 48 horas em meio YNB com $10 \%$ de etanol (v/v) e suplementação de aminoácidos (200 mg.L-1 de $\mathrm{N}$ amínico).

Tem sido proposto que a fenilalanina é necessária para o crescimento ótimo de $S$. cerevisiae em meios sintéticos (Hanscho et al., 2012; Crépin et al., 2012). Leveduras S. cerevisiae sintetizam fenilalanina e tirosina através do intermediário 4-hidroxifenilpiruvato e fenilpiruvato, respectivamente. A fenilalanina normalmente tem apenas três destinos metabólicos: incorporação em cadeias de polipéptidos; produção de tirosina através da hidroxilase de fenilalanina, que requer a tetrahidrobiopterina; e conversão para um álcool fusel (fusel oil). S. cerevisiae degrada os aminoácidos aromáticos (triptofano, fenilalanina e tirosina) e os aminoácidos de cadeia ramificada (valina, leucina e isoleucina) através da via de Ehrlich. Esta via consiste em 3 etapas: 1) desaminação do aminoácido para o ácido alfaceto correspondente; 2) descarboxilação do ácido alfaceto resultante do aldeído; e 3) redução do aldeído para formar o álcool de cadeia longa ou complexo correspondente, conhecido como álcool fusel ou óleo fusel (Braus, 1991). O óleo fúsel pode ser empregado como solvente na indústria de cosméticos e medicamentos, sendo sua principal aplicação na obtenção do álcool isoamílico para a síntese de acetato de amila ou isoamila (fixador para perfumes) (Güvenç et al., 2007). Na figura 2, O Controle 1 refere-se a D.O. em meio YNB com $12 \%$ de etanol (v/v) sem a adição de aminoácido no mesmo período. O Controle 2 refere-se a D.O. em meio YNB sem a adição de etanol e aminoácido no mesmo período. Letras iguais não diferem ao nível de $5 \%$ de significância $(\mathrm{p}<0,05)$, de acordo com o teste de Tukey. Análises estatísticas só foram calculadas para os tratamentos com etanol.

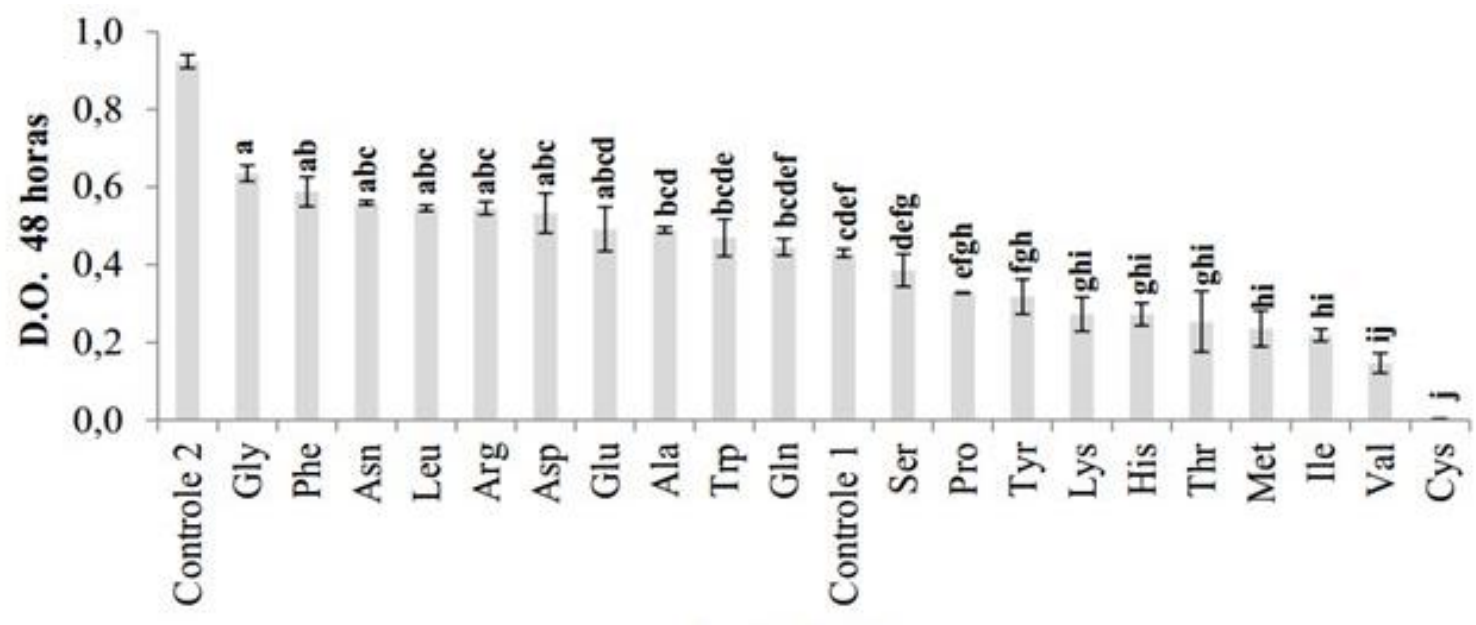

Aminoácidos

Figura 2 - Dados de D.O. (600nm) final e análises estatísticas da linhagem CAT-1 às 48 horas em meio YNB com $12 \%$ de etanol (v/v) e suplementação de aminoácidos (200 mg.L $\mathrm{L}^{-1}$ de $\mathrm{N}$ amínico). 
Um estudo relatou que quando as células de uma linhagem pertencente à espécie $S$. cerevisiae foram expostas a $20 \%$ de etanol (v/v), durante 9 horas a $30^{\circ} \mathrm{C}$, todas as células morreram. No entanto, $57 \%$ das células permaneceram viáveis quando a solução de etanol continha três aminoácidos: isoleucina, metionina e fenilalanina ( $\mathrm{Hu}$ et al., 2005). Com base nas análises de composição de aminoácidos e fluidez de membrana citoplasmática, por meio de anisotropia de fluorescência, usando difenil-hexatrieno como sonda, revelou-se que o aumento da tolerância ao etanol nas células de levedura foi devido à incorporação dos aminoácidos suplementares nas membranas citoplasmáticas, o que possivelmente levou à maior capacidade de neutralizar o efeito de fluidização exercido pelo etanol (Hu et al., 2005).

Sem a adição de etanol e aminoácido, CAT-1 apresentou uma D.O. de 0,924 neste mesmo período. A suplementação com cisteína causou o mesmo padrão de comportamento encontrado no teste anterior com $10 \%$ de etanol (Figura 1), pois com $12 \%$ de etanol (v/v), a linhagem apresentou uma D.O. de 0,003 (Figura 2). Isto ressalta a possibilidade de que a cisteína pode ter sido tóxica para a linhagem nestas condições. De acordo com Ono et al. (1999), linhagens de $S$. cerevisiae possuem vários mecanismos regulatórios para evitar a sobreprodução de cisteína e é provável que esta seja tóxica para a célula por conter um grupo -SH (composto organossulfurado) altamente reativo. Segundo o autor, a adição de cisteína a uma concentração de $50 \mu \mathrm{M}$, isto é $0,700 \mathrm{mgL}^{-1}$ de $\mathrm{N}$ amínico, provocou retardo e diminuição no crescimento, comportamento este atribuível à baixa atividade de transporte e assimilação de sulfato.

A adição de valina no meio YNB com $12 \%$ de etanol também causou depreciação no crescimento, sendo que não houve diferenças entre valina $(0,147)$ e cisteína no período de 48 horas. Derrick \& Large (1993) sugerem que uma quantidade significativa de valina pode ser metabolizada por rotas diferentes da via de Ehrlich, possivelmente por meio da ação de desidrogenase de cetoácidos de cadeia ramificada. Tais autores sugerem que a quebra de valina requer mais energia, sendo que no estudo dos mesmos foi obtido um rendimento de crescimento significativamente menor de $S$. cerevisiae em meio com valina como única fonte de $\mathrm{N}$. Vale ressaltar que nem todas as enzimas envolvidas no metabolismo de aminoácidos de cadeia ramificada em leveduras ainda foram identificadas, nem suas interações foram adequadamente compreendidas.

Em síntese, a adição dos aminoácidos Lys, His, Thr, Met, Ile, Val e Cys no meio YNB com $12 \%$ de etanol ocasionou uma diminuição significativa da D.O. (48 horas), em relação ao controle 1 (Figura
2). Ao verificar os dados revelados pelos testes com 10 e $12 \%$ de etanol (v/v), é possível sugerir que a suplementação com os diferentes aminoácidos pode causar comportamentos distintos, aumentando ou depreciando o crescimento, inclusive sob influência da concentração de etanol encontrada no meio YNB. Vale ressaltar que os aminoácidos não foram adicionados como única fonte de $\mathrm{N}$ no meio YNB. Sendo assim, os dados de crescimento aqui obtidos sofreram influência não somente da concentração de etanol fornecido, mas também do sulfato de amônio e ureia adicionados ao meio $(0,1 \%$ e $0,05 \%$, respectivamente).

\section{Testes de crescimento e determinação de nitrogênio assimilável em mosto de melaço de cana-de-açúcar}

Os testes nos quais se empregou o mosto de melaço de cana-de-açúcar foram realizados para avaliar tanto a influência dos aminoácidos no crescimento da linhagem CAT-1 em mostos com diferentes concentrações, quanto selecionar uma concentração adequada para os ensaios fermentativos subsequentes. No entanto, foi necessário verificar a dosagem de nitrogênio assimilável, isto é, $\mathrm{N}$ amínico mais $\mathrm{N}$ amoniacal, a fim de determinar uma concentração adequada para a suplementação dos aminoácidos nos testes de crescimento em melaço. A determinação de $\mathrm{N}$ assimilável revelou uma concentração de $227 \mathrm{mgL}^{-1} \mathrm{em}$ mosto proveniente do melaço da usina São Manoel, com 10\% de ART.

De acordo com Amorim et al. (1996), leveduras S. cerevisiae possuem um teor de $\mathrm{N}$ de $8 \%$, com base na matéria seca, constituindo as moléculas de aminoácidos, proteínas, enzimas, ácidos nucléicos, purinas, primidinas, pigmentos respiratórios (citocromos), vitaminas, etc. Em meio YEPD (2\% Dglicose, $1 \%$ de extrato de levedura e $1 \%$ de peptona bacteriológica) a levedura atinge uma biomassa úmida de cerca de $2 \%$, isto significa que é possível obter 20 g.L. L $^{-1}$ de biomassa úmida, ou 5 g.L - $^{-1}$ de biomassa seca (25\% da massa úmida). Portanto, 0,4 g.L. $\mathrm{L}^{-1}$ de $\mathrm{N}$ correspondem a 5 g. $\mathrm{L}^{-1}$ de biomassa seca, isto ao considerar que a levedura possui o teor de $8 \%$ de N, conforme descrito acima.

No crescimento aqui realizado, optamos por utilizar mostos de melaço de cana visando uma aproximação das condições encontradas nas destilarias brasileiras. Consideramos um teor final de $3 \%$ de biomassa úmida, e que para tal seria necessário 0,6 g.L. ${ }^{-1}$ de N. Sabendo que o mosto da usina São Manoel (10\% de ART) possui $227 \mathrm{mgL}^{-1}$ de $\mathrm{N}$ assimilável, e que a levedura precisa de $600 \mathrm{mgL}^{-1}$ de $\mathrm{N}$ para crescer $3 \%$, optamos por suplementar os mostos de melaço nos testes de crescimento com 200 
$\mathrm{mgL}^{-1}$ de $\mathrm{N}$ amínico proveniente dos diferentes aminoácidos. Desta forma, seria possível concentrar o mosto, levando em consideração que se aumentarmos a concentração do mosto, também estaríamos aumentando a concentração de N. Além disso, segundo Amorim \& Leão (2005), a utilização da concentração de $\mathrm{N}$ assimilável $\left(\mathrm{NH}_{4}{ }^{+}\right.$e $\left.\mathrm{R}-\mathrm{NH}_{2}\right)$ recomendada em mostos no processo fermentativo é de $100-300 \mathrm{mgL}^{-1}$.

O teste de crescimento empregando o mosto de melaço de cana com $15 \%$ de ART revelou que a suplementação com Val $(1,323)$ promoveu crescimento significativamente maior em relação ao controle (D.O. 1,059), após 48 horas de crescimento. Embora a presença da cisteína também tenha ocasionado depreciação no crescimento (0.909) no mosto de melaço, os dados não revelaram diferenças estatísticas em relação ao controle no mesmo período (48h) (Figura 3A). Estes resultados permitem compreender que o meio utilizado pode alterar totalmente o efeito da suplementação, aumentando ou diminuindo o crescimento da linhagem testada. Ou seja, o efeito no crescimento promovido por um aminoácido pode ser alterado, isto porque tal efeito pode ter influência do meio. É importante destacar que, em S. cerevisiae, as vias metabólicas envolvidas na síntese e utilização dos aminoácidos envolvem muitas vezes a presença de outros aminoácidos, revelando um mecanismo complexo e intrincado (Ljungdahl \& Daignan-Fornier, 2012). Segundo Clement et al. (2013), alterações metabólicas particulares podem ser desencadeadas de acordo com a natureza do aminoácido fornecido, além da resposta comum. A presença de alguns aminoácidos específicos pode favorecer a utilização de outros. Por exemplo, no presente estudo a suplementação com valina depreciou o crescimento em YNB com 10 e $12 \%$ de etanol (Figuras 1 e 2), e por outro lado, promoveu maior crescimento em mosto de melaço de cana com $15 \%$ de ART (Figura $3 \mathrm{~A})$.
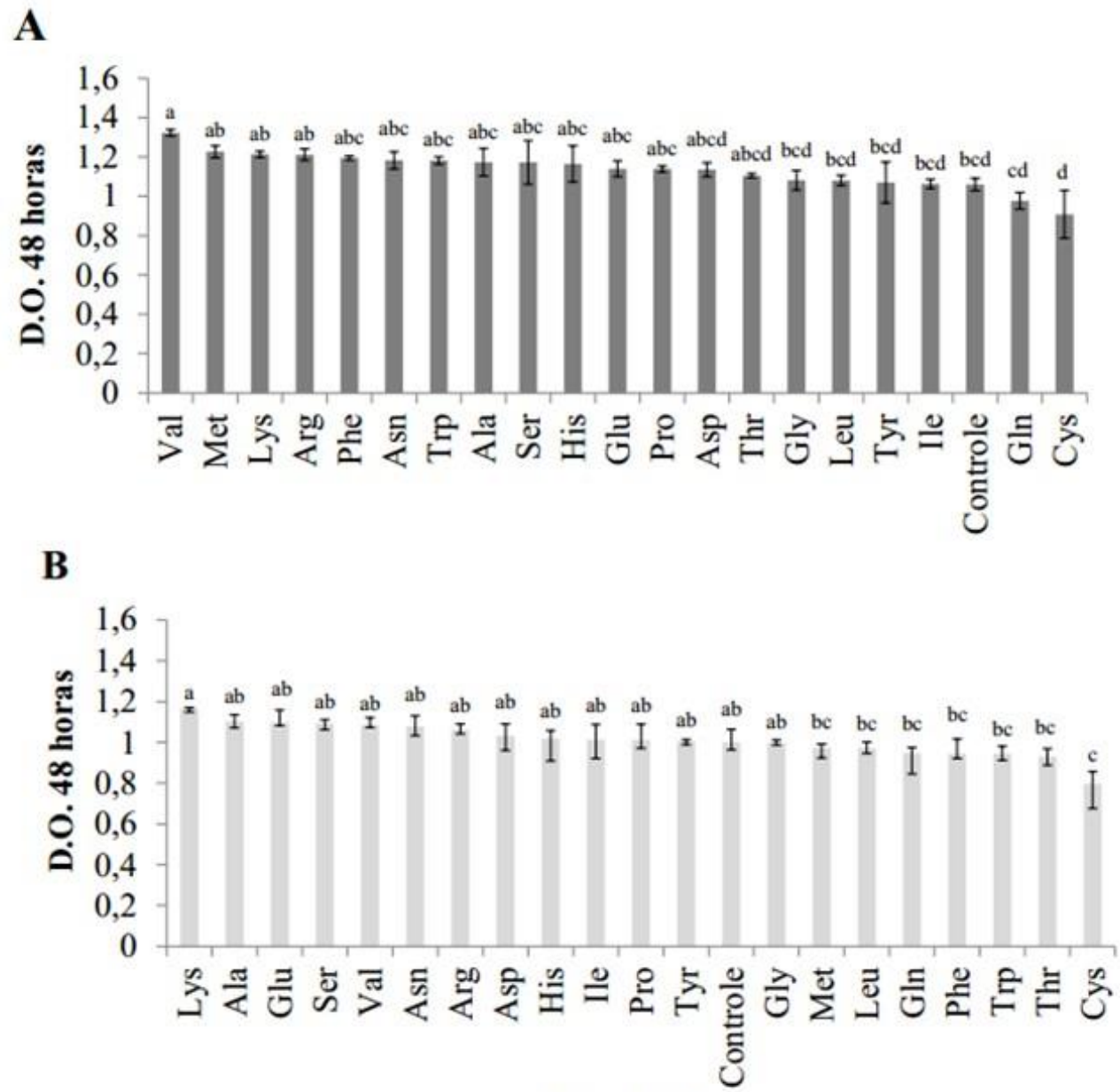

Aminoácidos

Figura 3 - Dados de D.O. (600nm) final e análises estatísticas da linhagem CAT-1 às 48 horas em mosto de melaço com 15\% (A) e 20\% (B) de ART e suplementação de aminoácidos (200 mgL-1 de N amínico). O controle refere-se a D.O. sem a adição de aminoácido no mesmo período. Letras iguais não diferem ao nível de $5 \%$ de significância $(\mathrm{p}<0,05)$. 
Portanto, descrever os diferentes efeitos no crescimento, promovidos pelos aminoácidos em mosto de melaço, possivelmente ajudaria a responder quais aminoácidos poderiam surtir efeitos positivos ou até mesmo negativos para a fermentação. $\mathrm{O}$ crescimento não é um fator primordial no tocante ao processo biotecnológico onde se emprega grande densidade de células, no entanto, é um indicativo de estresse em condições onde há pouca disponibilidade de oxigênio. Em condições microaeróbicas tais quais foram empregadas no presente trabalho (ensaios em microplacas), a linhagem pode apresentar menor crescimento, ou até mesmo nenhum, uma vez que o meio esteja promovendo efeitos deletérios para as células, como foi observado a partir da suplementação com Cys.

O teste de crescimento em mosto de melaço com $20 \%$ de ART revelou que a presença da cisteína depreciou significativamente o crescimento (D.O. 0,797) da linhagem CAT-1 no que se concerne ao controle sem a suplementação de aminoácido (D.O. 1,001) (Figura 3B). Os dados obtidos por todos os testes de crescimento aqui realizados apresentaram uma correlação no que diz respeito a suplementação com Cys. Tanto no meio YNB com 10 e $12 \%$ de etanol (\%,v/v) (Figuras 1 e 2), quanto em mosto de melaço com 20\% de ART (Figura 3B), a linhagem CAT-1 apresentou crescimento significativamente menor quando suplementada com $200 \mathrm{mgL}$ 1 de $\mathrm{N}$ amínico proveniente de Cys. Estes resultados enfatizam o trabalho de Ono et al. (1999), onde o mesmo ressaltou que é provável que a cisteína seja tóxica para a célula de $\mathrm{S}$. cerevisiae devido à sua posse de um grupo -SH altamente reativo.

Em mosto com $20 \%$ de ART, nenhuma outra suplementação, além de Cys, revelou diferença significativa em relação ao controle. Possivelmente o aumento da concentração do mosto levou a uma maior concentração de $\mathrm{N}$ total assimilável pela levedura. Este aumento pode ter contribuído para a disponibilidade máxima de $\mathrm{N}$ assimilável necessária. Sendo assim, pode-se inferir que por este motivo não foram observadas diferenças significativas, no que se refere ao propósito de maior crescimento da linhagem CAT-1 em relação ao controle sem a suplementação de aminoácido. Foram avaliadas concentrações ainda maiores, de 25 e $30 \%$ de ART no mosto de melaço. Os resultados não revelaram diferenças significativas referente ao crescimento de CAT-1 sem e com a suplementação de 200 mgL-1 de N amínico proveniente de aminoácido (Figuras suplementares 1 e 2). Portanto, o aumento da concentração do mosto de melaço, a partir de $15 \%$ de ART, possivelmente pode propiciar menor influência da suplementação de aminoácidos no crescimento da linhagem CAT-1 nas condições aqui empregadas. Entretanto, além do crescimento, outros parâmetros podem ser avaliados para a verificação da interferência da presença dos aminoácidos durante a fermentação alcoólica, e até mesmo validar o seu possível emprego no processo. Os parâmetros produção de etanol e viabilidade celular, por exemplo, também são fundamentais para avaliar o efeito dos diferentes aminoácidos na linhagem testada. Além disso, o teor de $\mathrm{N}$ da levedura com base na matéria seca é de $8 \%$, porém em leveduras durante a fermentação alcoólica este teor é mais baixo, de 5-6\% (Amorim et al., 1996). Portanto, nas fermentações posteriores com reciclo de células optamos por continuar a utilizar a concentração de $200 \mathrm{mgL}-1$ de N proveniente de aminoácidos, com a finalidade de avaliar os parâmetros de viabilidade celular e produções de biomassa e etanol.

\section{Experimentos fermentativos com suple- mentação de aminoácidos e reciclo de célu- las: fermentações em mosto de melaço de cana-de-açúcar}

A partir dos dados de D.O. obtidos pelos testes de crescimento em mosto de melaço, seis aminoácidos foram selecionados aleatoriamente dentre todos os que promoveram maior crescimento em relação ao controle, sem a suplementação de aminoácido, sendo eles: Ala, Arg, His, Lys, Ser e Val. Sete fermentações consecutivas foram realizadas a fim de verificar a influência da suplementação, dos aminoácidos selecionados, na viabilidade celular (\%), produção de biomassa (g) e produção de etanol $(\%, \mathrm{v} / \mathrm{v})$, ao final de cada ciclo. A suplementação dos aminoácidos foi de $200 \mathrm{mgL}-1$ de $\mathrm{N}$ amínico, sendo que para todos os tratamentos com os diferentes aminoácidos, a biomassa inicial foi de $0,85 \mathrm{~g}$ (Figura 4).

Com relação à produção de biomassa úmida $(\mathrm{g})$, não houve diferenças significativas nos dois primeiros ciclos, pois para todos os tratamentos, com e sem a suplementação, a linhagem CAT-1 apresentou uma média de 1,06 g nos ciclos 1 e 2 (Figura 4). Nos ciclos posteriores, $3,4,5,6$ e 7, a suplementação com Ala $(1,17,1,17,1,19,1,22$ e 1,29 g) e His $(1,17,1,17,1,17,1,22$ e $1,25 \mathrm{~g})$ ocasionou crescimento significativamente maior em relação ao controle $(1,03,1,04,1,04,1,08$ e 1,09 g) (Figura 4). A suplementação com Lys (1,15 e 1,19 g) também promoveu maior crescimento em relação ao controle nos ciclos 5 e 7. A presença de Arg, Ser e Val causou um crescimento significativamente igual ao controle em todos os ciclos fermentativos (Figura 4). Os dados de biomassa (g) demonstraram que a suplementação com Ala, His, e Lys estimulou maior crescimento da linhagem CAT-1 submetida em mosto de melaço de cana-de-açúcar. 


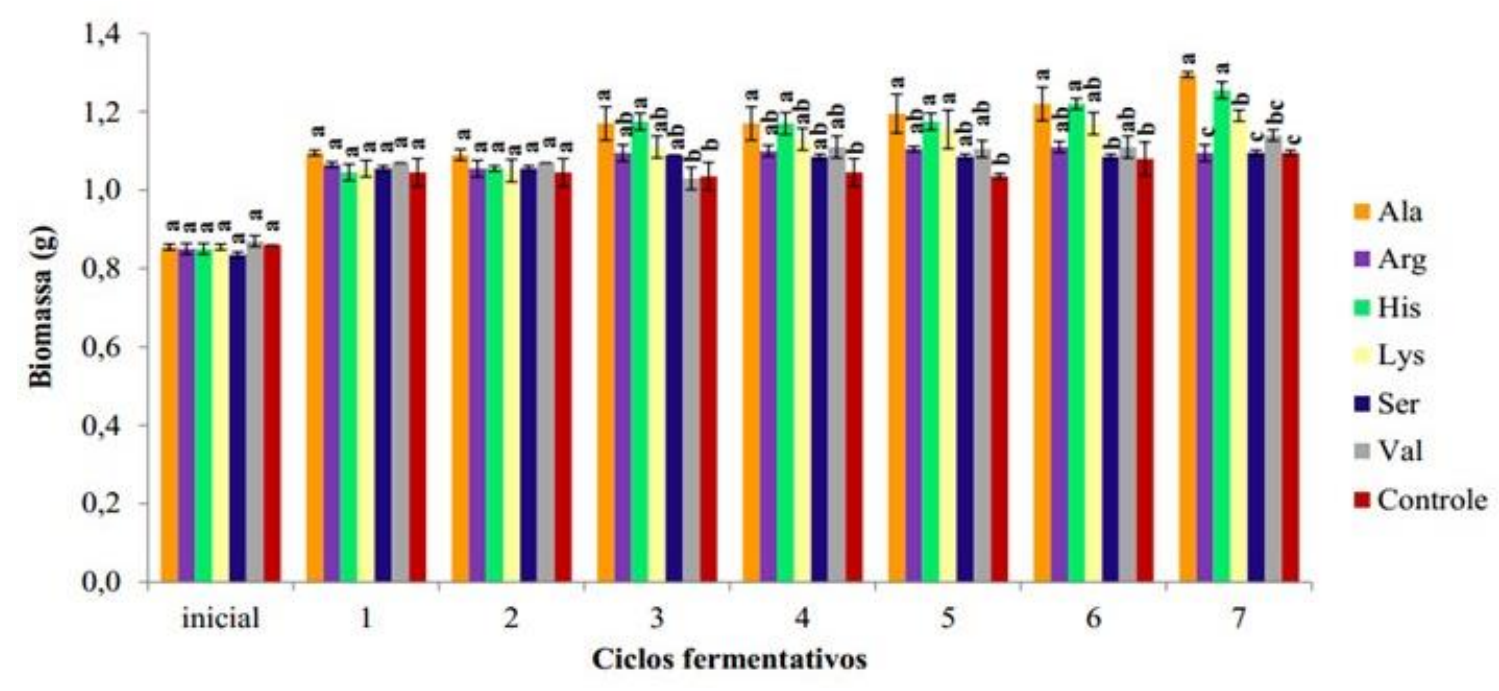

Figura 4 - Dados de produção de biomassa úmida (g) e análises estatísticas da linhagem CAT-1 em mosto de melaço de cana-de-açúcar com a suplementação de aminoácidos (200 mgL-1 de N amínico) ao final dos 7 ciclos fermentativos. O controle refere-se à biomassa ( $\mathrm{g}$ ) em mosto de melaço de cana-de-açúcar sem a suplementação de aminoácido. Letras iguais dentro do mesmo ciclo não diferem ao nível de $5 \%$ de significância $(\mathrm{p}<0,05)$

Blomqvist et al. (2012) investigaram o efeito de diferentes aminoácidos sobre o número de gerações de uma espécie não-Saccharomyces (Dekkera bruxellensis) em meio sintético sob condições anaeróbicas. Neste estudo, corroborando os dados aqui obtidos, a suplementação com Ala $(3,06)$, His $(3,29)$ e Lys $(3,51)$, também adicionada individualmente ao meio, aumentou significativamente o número de gerações da levedura em comparação com o controle $(1,04)$, sem a suplementação. Dawson (1965) mostrou que a presença de alanina aumentou a taxa de crescimento de uma linhagem de Candida utilis em uma cultura contínua com glicose como única fonte de carbono e limitação de NH4+.

Em S. cerevisiae, a Ala é degradada através da transaminação para piruvato pela enzima alanina aminotransferase. O piruvato é transportado para a mitocôndria, onde é decarboxilado oxidativamente em dióxido de carbono e acetil-CoA pelo complexo piruvato desidrogenase e, então, acetil-CoA entra no ciclo do ácido cítrico (Schlosser et al., 2004). Em condições respiratórias, a alanina aminotransferase desempenha um papel central na biossíntese e degradação da arginina. Em condição fermentativa, Saccharomyces cerevisiae sintetiza alanina por uma via alternativa, mas degrada a alanina pela mesma via a qual é produzida durante a respiração (García-Campusano et al., 2009).

Barton-Wright \& Thorne (1949) relataram que a presença dos aminoácidos Lys e His como nutriente nitrogenado para a levedura S. cerevisiae é de interesse considerável. Isto porque em seu estudo, referente à assimilação de 16 aminoácidos individuais em fermentação de mosto de cevada, verificou-se que a estes aminoácidos foram os primeiros aminoácidos a serem utilizados e, na conclusão da fermentação, foram assimilados praticamente por completo. Segundo os autores, as leveduras não podem remover o grupamento amino de Lys e His, sendo que a assimilação rápida, apesar de a levedura não realizar a desaminação dos mesmos, foi justificada pela hipótese de assimilação intacta de aminoácidos (Barton-Wright \& Thorne, 1949).

A produção de etanol $(\%, v / v)$ foi igual para todos os tratamentos, com e sem aminoácidos. À medida que se adicionou sacarose, a partir do ciclo 4, o etanol também aumentou. Nos ciclos 1, 2 e 3, onde foram utilizados mostos com $12 \%$ de ART, para todas as suplementações e controle, observaram-se médias de produção de 6,34, 6,86 e 6,55\% de etanol (v/v), respectivamente. Com o intuito de aumentar o estresse etanólico sem que ocorresse a concentração do melaço, foi adicionado $3 \%$ de sacarose no ciclo 4, e $5 \%$ de sacarose nos ciclos posteriores $(5,6$ e 7$)$. O objetivo de aumentar a produção de etanol foi ocasionar a diminuição do número de células viáveis e, deste modo, verificar se as diferentes suplementações de aminoácidos poderiam surtir efeitos na viabilidade da levedura. No ciclo 4, onde se empregou mosto com $15 \%$ de ART, a produção de etanol foi de 8,09\% (v/v). Nos ciclos 5, 6 e 7, em mostos com $20 \%$ de ART, os diferentes tratamentos e controle apresentaram médias de produção de 10,31, 10,43 e 10,46\% de etanol (v/v), respectivamente. Os dados de produção de etanol revelaram que nas condições em que o experimento foi conduzido, as diferentes suplementações não al- 
teraram a produção de etanol em relação ao controle.

Em relação à viabilidade, a linhagem CAT-1 iniciou o primeiro ciclo com $100 \%$ de viabilidade para todas as suplementações e controle. Conforme esperado e acima mencionado, a adição de açúcar a partir do ciclo 3 ocasionou queda no número de células viáveis (Figura 5). Não houve diferenças significativas na viabilidade celular nos ciclos 1,2 e 3 , para todos os tratamentos as médias de viabilidade foram de 99,75, 99,53 e 98,80\% (Figura 5). A suplementação com $200 \mathrm{mgL}-1$ de N amínico proveniente de Val apresentou valores de viabilidade de $93,14,86,31,75,51$ e $61,01 \%$ nos ciclos 4, 5, 6 e 7, respectivamente, sendo estes valores significativamente menores em relação ao controle $(99,64$, 97,29, 90,81 e 78,82\%) (Figura 5). A suplementação com Ser, também ocasionou queda na viabilidade a partir do ciclo 3. No entanto, diferenças estatísticas somente foram observadas no último ciclo, onde este tratamento apresentou uma viabilidade de $64,83 \%$, significativamente menor em comparação com o controle 78,82\% (Figura 5). As suplementações com Ala $(98,89$ e $86,80 \%)$, His
$(99,41$ e $99,10 \%)$ e Lys $(98,18$ e $86,94 \%)$ promoveram os maiores valores de viabilidade nos ciclos 6 e 7, em relação ao controle $(90,81$ e $78,82 \%)$ e aos outros tratamentos (Figura 5). O tratamento com His promoveu viabilidade significativamente maior em relação ao controle no ciclo 7 , sendo que esta suplementação promoveu os maiores valores de viabilidade em relação a todos os outros tratamentos e controle nos dois últimos ciclos (6 e 7) (Figura 5). Em síntese, os dados obtidos pelo presente experimento de fermentação revelaram que a presença de $200 \mathrm{mgL}-1$ de $\mathrm{N}$ amínico proveniente de Ala, His e Lys promoveram maior acúmulo de biomassa de CAT-1 em melaço de cana-de-açúcar (Figuras 4 e 5). A suplementação com Arg se mostrou igual ao controle no que se refere aos parâmetros de viabilidade (\%), produção de etanol $(\%, \mathrm{v} / \mathrm{v})$ e biomassa úmida $(\mathrm{g})$ ao final de todos os sete ciclos (Figura 4 e 5). Isto sugere que a presença de Arg na concentração de 200 mgL-1 de N amínico, em meio proveniente de mosto de melaço da usina São Manoel, não surtiu efeitos nos principais parâmetros fermentativos analisados.

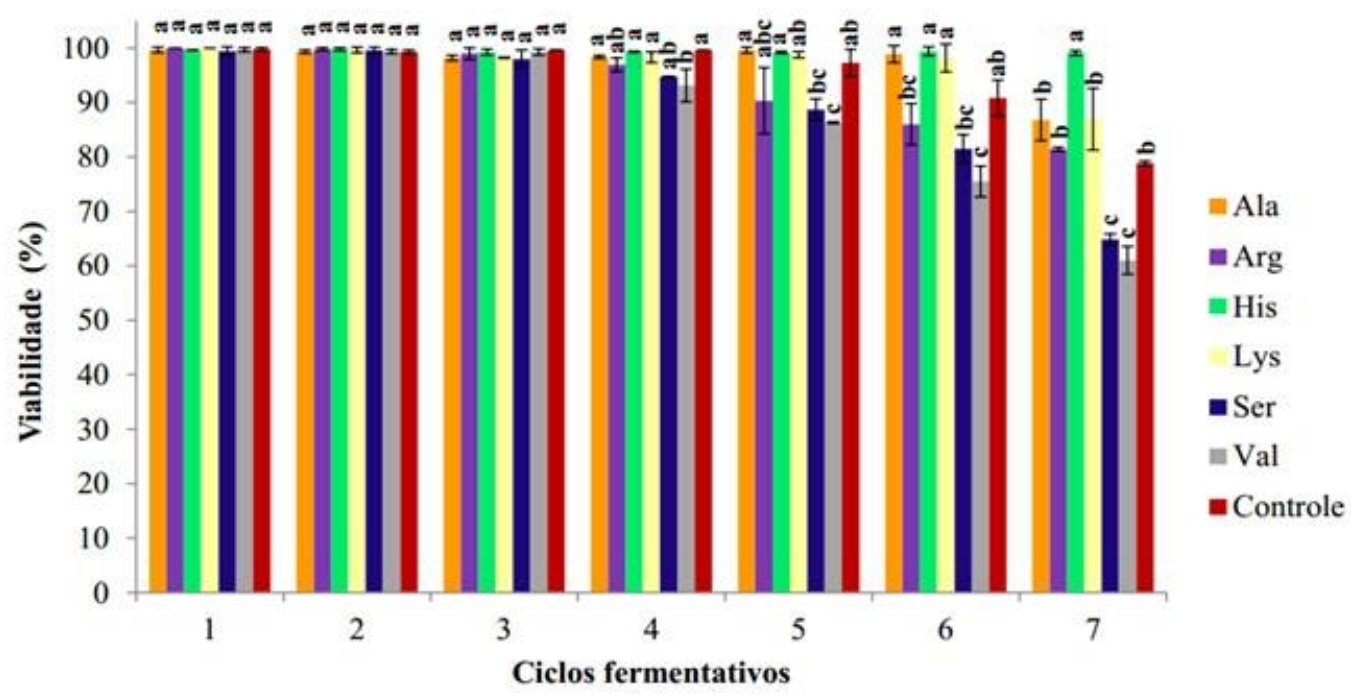

Figura 5 - Dados de viabilidade (\%) e análises estatísticas da linhagem CAT-1 em mosto de melaço de canade-açúcar com a suplementação de aminoácidos (200 mgL-1 de $\mathrm{N}$ amínico) ao final dos 7 ciclos fermentativos. O controle refere-se à viabilidade (\%) em mosto de melaço de cana-de-açúcar sem a suplementação de aminoácido. Letras iguais dentro do mesmo ciclo não diferem ao nível de $5 \%$ de significância $(\mathrm{p}<0,05)$.

Segundo Jones \& Fink (1982), em condições apropriadas, com carbono e NH4+suficientemente disponíveis, leveduras podem sintetizar todos os Laminoácidos. As famílias de aminoácidos derivados de uma molécula comum são facilmente identificáveis e incluem a família glutamato (glutamato, glutamina, arginina, prolina e lisina); a família aromática (fenilalanina, tirosina e triptofano); a família serina (serina, glicina, cisteína e metionina); a família aspartato (aspartato, asparagina, treonina e os aminoácidos que contêm enxofre cisteína e metionina); e a família dos piruvatos (alanina e aminoácidos ramificados valina, leucina e isoleucina). As vias de biossíntese de histidina e nucleotídeos estão conectadas. A importância do glutamato e da glutamina nas reações do núcleo central no metabolismo 
do nitrogênio é evidente, destacando seu envolvimento nas reações de transaminação necessárias na síntese de cada aminoácido (Magasanik \& Kaiser, 2002; Ljungdahl \& Daignan-Fornier, 2012).

Com relação à suplementação de aminoácidos na fermentação alcoólica, leveduras tendem a acumular o aminoácido fornecido e aqueles intimamente relacionados com ele metabolicamente, sendo que, uma concentração relativamente alta de ácido glutâmico é mantida na célula, independentemente da fonte de nitrogênio fornecida, refletindo o papel central do ácido glutâmico no metabolismo do nitrogênio (Watson, 1976). No estudo de Pham \& Wright (2008), a suplementação com uma mistura completa de aminoácidos (Complete Supplement Mixture of Sunrise Science Products) levou a respostas celulares positivas de S. cerevisiae, incluindo a redução do tempo de latência e maior viabilidade celular, em meios contendo alta concentração de açúcar (>200 g.L-1 de glicose). Além disso, verificou-se rendimentos de etanol aumentados $(0,43$ e $0,45 \mathrm{~g}$ de etanol por $\mathrm{g}$ de glicose $)$ a partir da suplementação. Neste mesmo estudo, por meio de análise proteômica quantitativa, utilizada para entender como S. cerevisiae suplementada com aminoácidos responde a condições de estresse osmótico, a maioria das proteínas envolvidas nas rotas da glicólise e pentoses fosfato tiveram suprarregulação (upregulation) em alta concentração de açúcar. A ativação do metabolismo de aminoácidos foi observada no final da fase Lag. A abundância relativa das proteínas mais identificadas, incluindo proteínas de biossíntese de aminoacil-tRNA (RNA transportador ligado a um aminoácido) e proteínas de choque térmico, permaneceu inalterada nas horas imediatamente após a adição da glicose. No entanto, a expressão dessas proteínas aumentou significativamente no final da fase Lag. Além disso, também se verificou a suprarregulação das proteínas de biossíntese de trealose e glicogênio. Esses dados, combinados com as medições relevantes dos metabólitos, demonstram que a partir da suplementação de aminoácidos é possível obter melhoria na fermentação alcoólica de meios com alta concentração de glicose por S. cerevisiae.

\section{Fermentações em mosto de xarope de cana- de-açúcar}

O xarope de cana-de-açúcar também pode ser utilizado em destilarias brasileiras e é constituído de menor quantidade de nutrientes e fonte de nitrogênio em comparação com o melaço. Mais frequentemente vem a ser a concentração do caldo de cana para se aumentar o teor de ART, sendo que tal substrato se assemelha ao xarope convenientemente diluído para a fermentação. Por este motivo, também foram realizadas fermentações em mosto de xarope a fim de avaliar a influência da suplementação de aminoácidos (200 mgL-1 de N amínico) nos principais parâmetros da fermentação: biomassa (g), etanol $(\%, v / v)$ e viabilidade celular (\%). Neste ensaio fermentativo, em apenas três ciclos já foram verificadas diferenças significativas em relação à produção de biomassa e viabilidade nos diferentes tratamentos com aminoácidos. Tais diferenças possivelmente foram observadas por ter sido empregado mosto de xarope a uma concentração de $20 \%$ desde o primeiro ciclo, para que fosse possível obter teores mais elevados de etanol e, por conseguinte, ocasionar uma diminuição do número de células viáveis. A partir dos dados obtidos pelo experimento fermentativo anterior, no qual se empregou mosto de melaço de cana-de-açúcar, foram selecionados os aminoácidos Ala, Lys e His, por terem favorecido a linhagem CAT-1 em relação ao crescimento e a viabilidade (item 3.3.1). Os aminoácidos Asn, Glu e o Trp também foram selecionados para a fermentação em xarope de cana, pois a presença dos mesmos aumentou o crescimento de CAT-1 nos ensaios em microplacas, tanto em meio YNB com $12 \%(\mathrm{v} / \mathrm{v})$ de etanol (Figura 2), quando em mosto de melaço com 15\% de ART (Figura 3A). Além disso, o Trp e o Glu são aminoácidos bastante citados na literatura por promoverem crescimento e resistência a diferentes tipos de estresse em S. cerevisiae (Hirasawa et al., 2007; Yoshikawa, et al., 2009; Godin et al., 2016; Thomas \& Ingledew, 1990; TerSchure et al., 1998; Wu et al., 2013).

Em todos os tratamentos a linhagem CAT-1 iniciou a primeira fermentação com $0,76 \mathrm{~g}$ de biomassa úmida, coletada da etapa de propagação. Já no primeiro ciclo, a suplementação com His $(1,04$ g) ocasionou um crescimento significativamente maior do que o controle $(0,92 \mathrm{~g})$ e os demais tratamentos analisados (Figura 6). A presença de Lys $(0,98 \mathrm{~g})$ também promoveu crescimento significativamente maior do que o controle e não diferiu em relação a Ala $(0,94)$ e Trp $(0,95)$. No primeiro ciclo, Asn, Glu, Ala e Trp não diferiram do controle, sem a suplementação, em relação à produção de biomassa em mosto de xarope de cana (Figura 6).

No segundo e terceiro ciclo a presença de His no xarope também promoveu maior crescimento $(1,14$ e $1,18 \mathrm{~g})$ em comparação com o controle (1,06 e $1,06 \mathrm{~g}$ ) e os demais tratamentos (Figura 6). Embora o glutamato tenha sido descrito na literatura como provedor de crescimento em leveduras S. cerevisiae (Hirasawa et al., 2007; Yoshikawa, et al., 2009; Godin et al., 2016; Thomas \& Ingledew, 1990; TerSchure et al., 1998; Wu et al., 2013), em mosto de xarope nas condições aqui descritas, o mesmo não ocasionou maior crescimento em relação ao controle em nenhum dos ciclos.

No ciclo 2, as suplementações com Glu, Ala, 
Asn e Trp apresentaram 0,97, 0,99, 1,03 e 1,03 g de biomassa, respectivamente, sendo estes valores significativamente menores do que o controle. A su- plementação com Lys (1,05 g) não diferiu do controle com relação à produção de biomassa no segundo ciclo fermentativo (Figura 6).

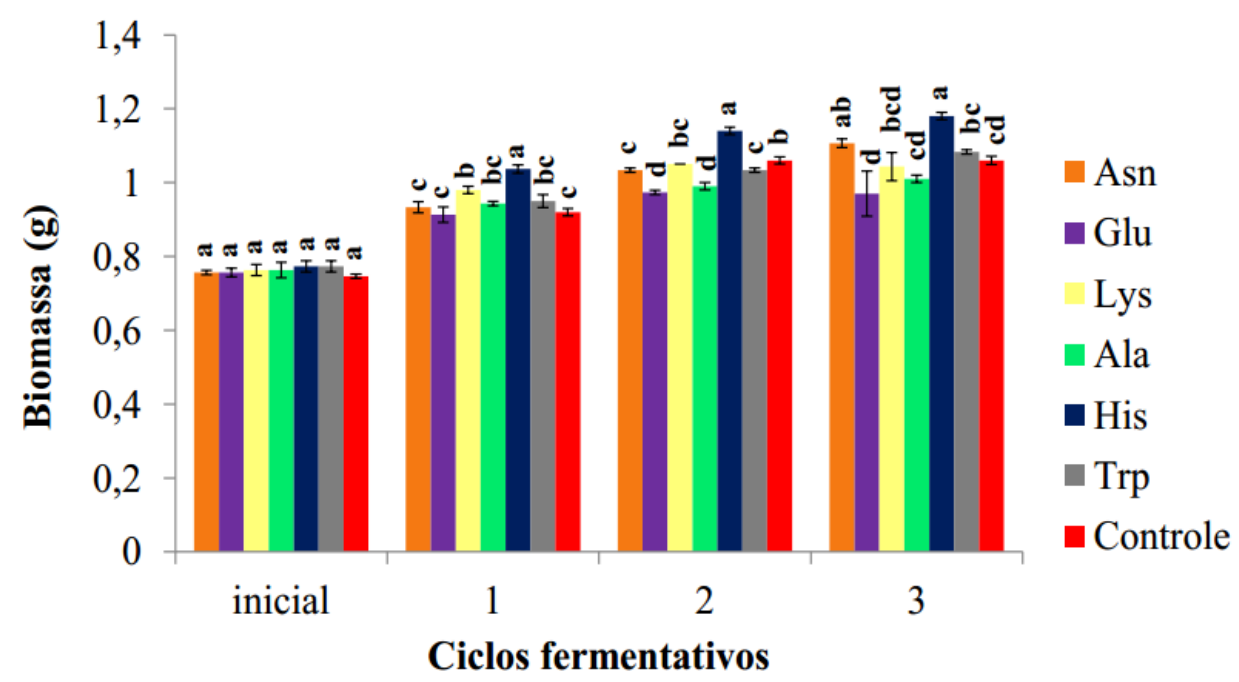

Figura 6 - Dados de produção de biomassa úmida (g) e análises estatísticas da linhagem CAT-1 em mosto de xarope de cana-de-açúcar com a suplementação de aminoácidos (200 mgL-1 de $\mathrm{N}$ amínico) ao final dos 3 ciclos fermentativos. O controle refere-se à biomassa $(\mathrm{g})$ em mosto de melaço de cana-de-açúcar sem a suplementação de aminoácido. Letras iguais dentro do mesmo ciclo não diferem ao nível de 5\% de significância $(\mathrm{p}<0,05)$.

No terceiro e último ciclo, além da His ter promovido maior crescimento significativamente, a presença de Asn $(1,11 \mathrm{~g})$ também demonstrou maior produção significativa de biomassa úmida em relação ao controle. A suplementação com o Glu $(0,97 \mathrm{~g})$ apresentou menor acúmulo de biomassa em relação a todos os outros tratamentos no último ciclo. Os aminoácidos Lys (1,04 g), Ala $(1,01)$ e Trp $(1,08)$ demostraram acúmulos de biomassa similares ao controle, no ciclo 3 (Figura 6).

Em síntese, a presença de His e Asn, em fermentações de xarope de cana, promoveu maior crescimento da linhagem CAT-1. Os dados de produção de biomassa sugerem que embora His também tenha favorecido CAT-1 em fermentações de mosto de melaço, não há um padrão para o efeito dos tratamentos com os aminoácidos testados. Isto porque, outros aminoácidos (Ala e Lys) apresentaram maior produção de biomassa em mosto de melaço em comparação com o controle, e por outro lado, apresentaram resultados similares ao controle no mosto de xarope de cana. Ou seja, ao alterar o mosto, com fonte de minerais e $\mathrm{N}$ diferentes, possivelmente também se modifica o efeito dos aminoácidos, alterando o perfil fisiológico da levedura. Não obstante, His promoveu maior crescimento da linhagem CAT-1 em ambos os mostos aqui testados.

As análises de produção de etanol $(\%, v / v)$ não revelaram diferenças significativas para os diferentes tratamentos com aminoácidos e o controle sem a suplementação. As médias de produção, considerando todos os aminoácidos e controle, para os ciclos 1, 2 e 3 são de $11,61,13,38$ e 13,71\% de etanol $(\mathrm{v} / \mathrm{v})$.

Com relação à viabilidade celular, todos os tratamentos, com e sem aminoácido, iniciaram a primeira fermentação em xarope com $100 \%$ de viabilidade. Ao contrário das fermentações em mosto de melaço de cana, a suplementação com Ala em xarope diminuiu a viabilidade celular de CAT-1 em todos os três ciclos: $90,67 \%$ no primeiro, $78,67 \%$ no segundo e 77,00\% no terceiro (Figura 7). Este dado enfatiza a possibilidade de que os aminoácidos possam atuar de maneiras distintas de acordo com o mosto/meio utilizado.

No terceiro ciclo, a presença dos aminoácidos Trp $(98,50)$, Asn $(98,50)$ e His $(95,00)$ apresentaram valores de viabilidade significativamente maiores em relação ao controle $(86,00 \%)$ (Figura 7$)$. A presença de Glu, mesmo que tenha apresentado menor acúmulo de biomassa (Figura 6), apresentou o valor de viabilidade de $85,50 \%$, similar ao controle no último ciclo (Figura 7). A suplementação com Lys $(88,40 \%)$ também não diferiu do controle no quesito viabilidade de células.

Em mosto de xarope, a suplementação com His 
e Asn favoreceu a linhagem em relação ao crescimento e viabilidade. No último ciclo, mesmo que a presença de Trp não tenha aumentado a produção de biomassa, favoreceu a linhagem para a maior viabilidade em fermentações de xarope nas condições aqui empregadas.

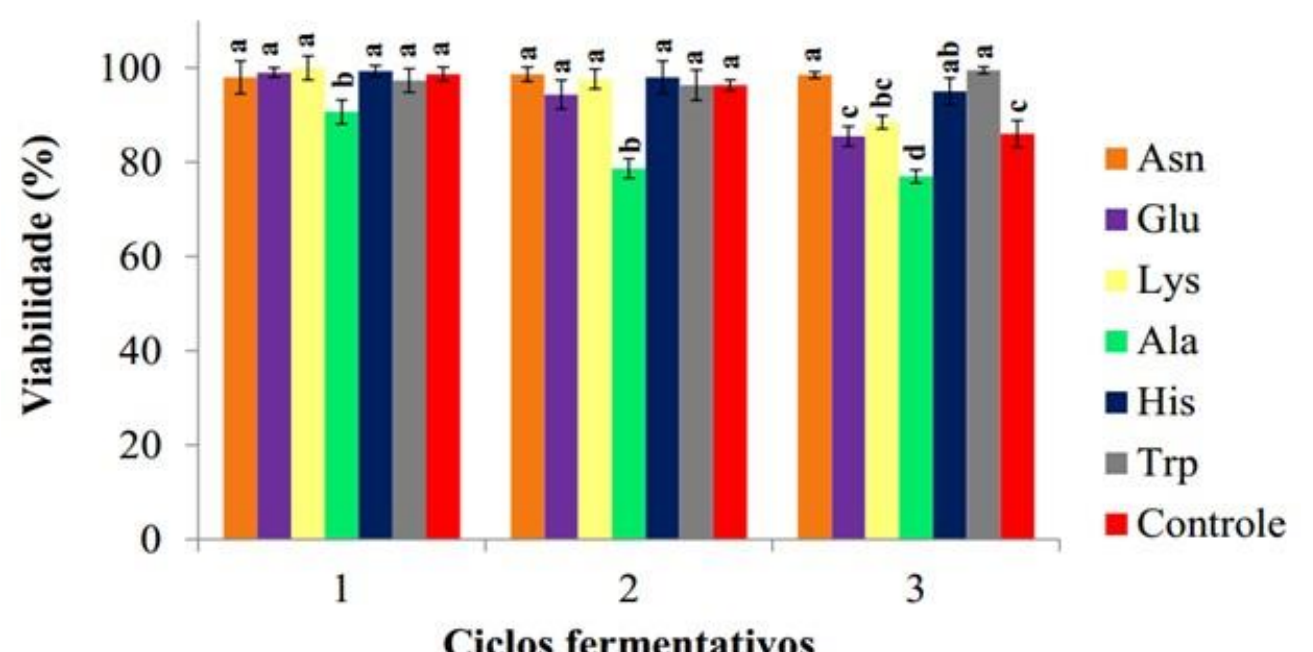

Figura 7 - Dados de viabilidade (\%) e análises estatísticas da linhagem CAT-1 em mosto de xarope de canade-açúcar com a suplementação de aminoácidos (200 mgL-1 de $\mathrm{N}$ amínico) ao final dos 3 ciclos fermentativos. O controle refere-se à viabilidade (\%) em mosto de melaço de cana-de-açúcar sem a suplementação de aminoácido. Letras iguais dentro do mesmo ciclo não diferem ao nível de $5 \%$ de significância $(p<0,05)$.

\section{CONCLUSÕES}

A concentração de $200 \mathrm{mgL}-1$ de nitrogênio amínico, utilizada nos diferentes tratamentos com aminoácidos, em meio YNB e em mostos de melaço e xarope de cana, foi eficaz para o intuito de diferenciar comportamentos fisiológicos da linhagem CAT-1. A partir dos dados obtidos - tanto pelos testes de crescimento em microplacas, quanto pelas fermentações com reciclo de células - é possível afirmar que a suplementação com aminoácidos pode ocasionar efeitos distintos no comportamento fisiológico da levedura CAT-1 de acordo com o meio/mosto empregado. Isto porque, alterando o meio verificou-se uma mudança comportamental em relação ao crescimento e viabilidade da linhagem para a maioria dos aminoácidos testados. Possivelmente, isto se deve ao fato de que os aminoácidos possuem vias metabólicas complexas, compreendendo um mecanismo intrincado, muitas vezes dependendo da presença de outros para que ocorra a sua assimilação/metabolização. Embora este comportamento tenha sido observado para a maior parte dos aminoácidos aqui testados, a suplementação com His apresentou um padrão de comportamento, favorecendo a linhagem CAT-1 para maior crescimento e viabilidade em mostos provenientes tanto de melaço quanto de xarope de cana- de-açúcar. Todos estes dados sugerem que a suplementação com His poderia ser uma potencial fonte de $\mathrm{N}$ ou uma molécula protetora aos estresses encontrados em fermentações de mostos de melaço e xarope de cana. Os resultados revelados pelo presente estudo apontam que a suplementação de 200 mgL-1 de $\mathrm{N}$ amínico proveniente de alguns aminoácidos, em mostos de melaço e xarope de cana, pode favorecer ou depreciar o crescimento e viabilidade da linhagem CAT-1 em fermentações simulando as condições industriais brasileiras, com reciclo de células.

\section{REFERÊNCIAS BIBLIOGRÁFICAS}

ALBERS, E.; LARSSON, C.; LIDÉN, G.; NIKLASSON, C.; GUSTAFSSON, L. Influence of the nitrogen source on Saccharomyces cerevisiae anaerobic growth and product formation. Applied and Environmental Microbiology, v. 62, n. 9, p. 3187-3195, 1996.

AMORIM, H.V.; BASSO, L.C.; ALVES, D.M.G. Processos de produção de álcool: controle e monitoramento. Piracicaba, FERMENTEC, 1996. 103p.

AMORIM, H.V.; LEÃO, R.M. Fermentação alcoólica: ciência e tecnologia. Piracicaba, FERMENTEC, 2005. 448p.

BADOTTI, F.; DÁRIO, M.G.; ALVES, S.L.JR.; CORDIOLI, M.L.; MILETTI, L.C.; DE ARAUJO, P.S.; STAMBUK, B.U. Switching the mode of sucrose utilization by Saccharomyces cerevisiae. Microbial Cell Factories, v. 7, n. 4, p. 1-11, 2008. 
BARTON-WRIGHT, E.C.; THORNE, R.S.W. Utilization of amino acids during yeast growth in wort. Journal of The institute of Brewing, v. 55, n. 6, p. 383-386, 1949.

BASSO, L.C.; AMORIM, H.V. Produção de etanol. In: Lima, U.A. (Ed.). Biotecnologia industrial: processos fermentativos e enzimáticos. Edgard Blucher, 2001, cap. 1, p. $1-43$.

BASSO, L.C.; AMORIM, H.V.; OLIVEIRA, A.J.; LOPES, M.L. Yeast selection for fuel ethanol in Brazil. FEMS Yeast Research, v. 8, n. 7, p. 1155-1163, 2008.

BASSO, L.C.; BASSO, T.O.; ROCHA, S.N. Ethanol production in Brazil: the industrial process and its impact on yeast fermentation. In: SANTOS BERNARDES, M.A. (Ed.). Biofuel Production - Recent Developments and Prospects. InTech, 2011, chap. 5, p. 85-100.

BLOMQVIST, J.; NOGUÉ, V.S.; GORWA-GRAUSLUND, M.; PASSOTH, V. Physiological requirements for growth and competitiveness of Dekkera bruxellensis under oxygen-limited or anaerobic conditions. Yeast, v. 29, n. 7, p. 265-274, 2012.

BRAUS, G.H. Aromatic amino acid biosynthesis in the yeast Saccharomyces cerevisiae: a model system for the regulation of a eukaryotic biosynthetic pathway. Microbiological Reviews, v. 55, n. 3, p. 349-370, 1991.

CHEN, J.C.P. Analysis of juice. In: Chen, J.C.P.; Chou, C.C. (Eds.). Cane Sugar Handbook - A Manual for Cane Sugar Manufacturers and Their Chemists. John Wiley \& Sons Inc, 1993, cap. 42, p. 931-940.

CLEMENT, T.; PEREZ, M.; MOURET, J.R.; SANCHEZ, I.; SABLAYROLLES, J.M.; CAMARASA, C. Metabolic responses of Saccharomyces cerevisiae to valine and ammonium pulses during four-stage continuous wine fermentations. Applied Environmental Microbiology, v. 79, n. 8, p. 2749-2758, 2013.

CRÉPIN, L.; NIDELET, T.; SANCHEZ, I.; DEQUIN, S.; CAMARASA, C. Sequential use of nitrogen compounds by saccharomyces cerevisiae during wine fermentation: a model based on kinetic and regulation characteristics of nitrogen permeases. Applied and Environmental Microbiology, v. 78, n. 22, p. 8102-8111, 2012.

DAWSON, P.S.S. The Intracellular amino acid pool of Candida utilis during growth in batch and continuous flow cultures. Biochimica et Biophysica Acta, v. 3, p. 51-66, 1965.

DERRICK, S.; LARGE, P.J. Activities of the enzymes of the Ehrlich pathway and formation of branched-chain alcohols in Saccharomyces cerevisiae and Candida utilis grown in continuous culture on valine or ammonium as sole nitrogen source. Journal of General Microbiology, v. 139, n. 11, p. 2783-2792, 1993.

FILIPE-RIBEIRO, L.; MENDES-FAIA, A. Validation and comparison of analytical methods used to evaluate the nitrogen status of grape juice. Food Chemistry, v. 100, n. 3 , p. 1272-1277, 2007.

GARCÍA-CAMPUSANO, F.; ANAYA, V.H.; ROBLEDOARRATIA, L.; QUEZADA, H.; HERNÁNDEZ, H.; RIEGO, L.; GONZÁLEZ, A. ALT1-encoded alanine aminotransferase plays a central role in the metabolism of alanine in Saccharomyces cerevisiae. Canadian Journal of Microbiology, v. 55, n. 4, p. 368-374, 2009.
GODIN, S.K.; LEE, A.G.;, BAIRD J.M.; HERKEN, B.W.; BERNSTEIN, K.A. Tryptophan biosynthesis is important for resistance to replicative stress in Saccharomyces cerevisiae. Yeast, v. 35, n. 5, p. 183-189, 2016.

GÜVENÇ, A.; KAPUCU, N.; KAPUCU,H.; AYDOĞAN, Ö; MEHMETOĞLU, Ü. Enzymatic esterification of isoamyl alcohol obtained from fusel oil: Optimization by response surface methodolgy. Enzyme and Microbial Technology, v. 40, n. 4 , p. $778-785,2007$.

HANSCHO, M.; RUCKERBAUER, D.E.; CHAUHAN, N.; HOFBAUER, H.F.; KRAHULEC, S.; NIDETZKY, B.; KOHLWEIN, S.D.; ZANGHELLINI J.; NATTER, K. Nutritional requirements of the BY series of Saccharomyces cerevisiae strains for optimum growth. FEMS Yeast Research, v. 12, n. 7, p. 796-808, 2012.

HIRASAWA, T; YOSHIKAWA, K.; NAKAKURA, Y.; NAGAHISA, K.; FURUSAWA, C.; KATAKURA, Y.; SHIMIZU, H.; SHIOYA, S. Identification of target genes conferring ethanol stress tolerance to Saccharomyces cerevisiae based on DNA microarray data analysis. Journal of Biotechnology, v. 131, n. 1, p. 34-44, 2007.

HU, C.K.; BAI, F.W.; AN, L.J. Protein amino acid composition of plasma membranes affects membrane fluidity and thereby ethanol tolerance in a self-flocculating fusant of Schizosaccharomyces pombe and Saccharomyces cerevisiae. Sheng Wu Gong Cheng Xue Bao, v. 21, n. 5, p. 809-813, 2005.

JERONIMO, E.M.; SOUZA, E.L.R.; SILVA, M.A.; CRUZ, J.C.S.; GAVA, G.J.C.; SERRA, G.E. Isolado protéico de soja como fonte de nitrogênio na fermentação alcóolica. Boletim Ceppa, v.26, n.1, p. 21-28, 2008.

JONES, E.W.; FINK G.R. Regulation of amino acid and nucleotide biosynthesis in yeast. In: Strathern, J.N.; Jones, E.W.; Broach, J.R. (Eds.). The Molecular Biology of the Yeast Saccharomyces: Metabolism and Gene Expression. Cold Spring Harbor Laboratory Press, 1982, cap. 5, p. 181299.

KALMOKOFF, M.L; INGLEDEW, W.M. Evaluation of ethanol tolerance in selected Saccharomyces strains. Journal of the American Society of Brewing Chemists, v. 43, p. 190-196, 1985.

LJUNGDAHL, P.O. Amino-acid-induced signalling via the SPS-sensing pathway in yeast. Biochemical Society Transactions, v. 37, p. 242-247, 2009.

LJUNGDAHL, P.O.; DAIGNAN-FORNIER, B. Regulation of amino acid, nucleotide, and phosphate metabolism in Saccharomyces cerevisiae. Genetics, v. 190, n. 3, p. 885929, 2012.

LOPES, M.L.; PAULILLO, S.C.L.; GODOY, A.; CHERUBIN, R.A.; LORENZI, M.S.; GIOMETTI, F.H.C.; BERNARDINO, C.D.; AMORIM-NETO, H.B.; AMORIM, H.V. Ethanol production in Brazil: a bridge between science and industry. Brazilian Journal of Microbiology, v. 47S, p. 64-76, 2016.

MAGASANIK, B.; KAISER, C.A. Nitrogen regulation in Saccharomyces cerevisiae. Gene, v. 290, n. 1-2, p. 1-18, 2002. 
MORITA, Y.; NAKAMORI, S.; TAKAGI, H. Effect of proline and arginine metabolism on freezing stress of Saccharomyces cerevisiae. Journal of Bioscience and Bioengineering, v. 94, n. 5, p. 390-394, 2002.

OLIVEIRA, A.J.; GALLO, C.R.; ALCARDE, V.E.; GODOY, A.; AMORIM, H.V. Métodos para o controle microbiológico na produção de álcool e açúcar. Piracicaba: FERMENTEC/FEALQ/ESALQ-USP, 1996. 89p.

ONO, B.I.; HAZU, T.; YOSHIDA, S.; KAWATO, T.; SHINODA, S.; BRZVWCZY, J.; PASZEWSKI, A. Cysteine biosynthesis in Saccharomyces cerevisiae: a new outlook on pathway and regulation. Yeast, v. 15, n. 13, p. 1365$1375,1999$.

PETERS, D. Carbohydrates for fermentation. Biotechnology Journal, v. 1, n. 7-8, p. 806-814, 2006.

PHAM, T.K.; WRIGHT, T.K. The proteomic response of Saccharomyces cerevisiae in very high glucose conditions with amino acid supplementation. Journal of Proteome Research, n. 7, p. 4766-4774, 2008.

PIPER, M.; HONG, S.; BALL, G.; DAWES, I. Regulation of the balance of one-carbon metabolism in Saccharomyces cerevisiae. The Journal of Biological Chemistry, v. 275, n. 40, p. 30987-30995, 2000.

SCHLÖSSER, T.; GÄTGENS, C.; WEBER, U.; STAHMANN, K.P. Alanine: glyoxylate aminotransferase of Saccharomyces cerevisiae-encoding gene AGX1 and metabolic significance. Yeast, v. 21, n. 1, p. 63-73, 2004.

SINCLAIR, D.; DAWES, I. Genetics of the synthesis of serine from glycine and the utilization of glycine as sole nitrogen source by Saccharomyces cerevisiae. Genetics, v. 140, n. 4, p. 1213-1222, 1995.

TAKAGI, H. Proline as a stress protectant in yeast: physiological functions, metabolic regulations, and biotechnological applications. Applied Microbiology and Biotechnology, v. 81, n. 2, p. 211-223, 2008.

TAKAGI, H.; IWAMOTO, F.; NAKAMORI, S. Isolation of freeze-tolerant laboratory strains of Saccharomyces cerevisiae from proline-analogue-resistant mutants. Applied Microbiology and Biotechnology, v. 47, n. 4, p. 405-411, 1997.

TER-SCHURE, E.G.; SILLJÉ, H.H.; VERMEULEN, E.E.; KALHORN, J.W.; VERKLEIJ, A.J.; BOONSTRA, J.; VERRIPS, C.T. Repression of nitrogen catabolic genes by ammonia and glutamine in nitrogen-limited continuous cultures of Saccharomyces cerevisiae. Microbiology, v. 144, n. 5, p. 1451-1462, 1998.

THOMAS, K.C.; INGLEDEW, W.M. Fuel alcohol production: effects of free amino nitrogen on fermentation of very-high-gravity wheat mashes. Applied and Environmental Microbiology, v. 57, n. 7, p. 2046-2050, 1990.

TROPEA, A.; WILSON, D.; CICERO, N.; POTORTÌ, A.G.; LA TORRE, G.L.; DUGO, G.; RICHARDSON, D.; WALDRON, K.W. Development of minimal fermentation media supplementation for ethanol production using two Saccharomyces cerevisiae strains. Natural Product Research, v. 30, n. 9, p. 1009-1016, 2016.

WATSON, T.G. Amino-acid pool composition of Saccharomyces cerevisiae as a function of growth rate and amino- acid nitrogen source. Journal of General Microbiology, v. 96, n. 2, p. 263-268, 1976.

WOICIECHOWSKI, A.L.; CARVALHO, J.C.; SPIER, M.R.; SOCCOL, C. Emprego de resíduos agroindustriais em bioprocessos alimentares. In: Bicas, J.L.; Maróstica, M.R.; Pastore, G.M. (Eds.). Biotecnologia de alimentos. Atheneu Editora, 2013, cap. 6, p. 143-171.

WU, G. Amino acids: metabolism, functions, and nutrition. Amino Acids, v. 37, n. 1, p. 1-17, 2009.

WU, Z.; SONG, L.; LIU, S.Q.; HUANG, D. Independent and additive effects of glutamic acid and methionine on yeast longevity. PLoS One, v. 8, n. 11, p. 1-13, 2013.

YOSHIKAWA, K.; TANAKA, T.; FURUSAWA, C.; NAGAHISA, K.; HIRASAWA, T.; SHIMIZU, H. Comprehensive phenotypic analysis for identification of genes affecting growth under ethanol stress in Saccharomyces cerevisiae. FEMS Yeast Research, v. 9, n. 1, p. 32-44, 2009. 